NASA Technical Memorandum 106279

ALAA-93-2522

$176 \% 22$

$P, 13$

\title{
A Comparison Between Numerically Modelled and Experimentally Measured Loss Mechanisms in Wave Rotors
}

Daniel E. Paxson

Lewis Research Center

Cleveland, Ohio

Prepared for the

29th Joint Propulsion Conference and Exhibit sponsored by the AIAA, SAE, ASME, and ASEE

Monterey, California, June 28-30, 1993 


\title{
A COMPARISON BETWEEN NUMERICALLY MODELLED AND EXPERIMENTALLY MEASURED LOSS MECHANISMS IN WAVE ROTORS
}

\author{
Daniel E. Paxson* \\ Lewis Research Center \\ Cleveland, Ohio
}

\begin{abstract}
A numerical model has been developed which is capable of predicting the performance of a wave rotor (pressure exchanger) of specified geometry over a wide range of operating conditions. The model can account for the major loss mechanisms of leakage from the tube ends, fluid viscosity, heat transfer to the tube walls, finite tube opening time, shock waves, and non-uniform port flows. It is a one dimensional flow model which follows a single tube as it rotates past the various stationary ports. Since the model is relatively simple (i.e. one dimensional) it uses little computer time. This makes it suitable for design as well as analytical purposes. This paper will present a brief description of the model then discuss a comparison between the model predictions and several wave rotor experiments.
\end{abstract}

\subsection{Introduction}

The wave rotor represents a promising technology for achieving high overall pressure ratios and peak cycle temperatures in future gas turbine engines. Shown schematically in Figure 1 , the wave rotor is a device which utilizes unsteady waves to transfer energy to and from the working fluid passing through it. Detailed descriptions of the principles of operations may be found in numerous references ${ }^{1,2,3,4,5,6}$ and will not be presented here.

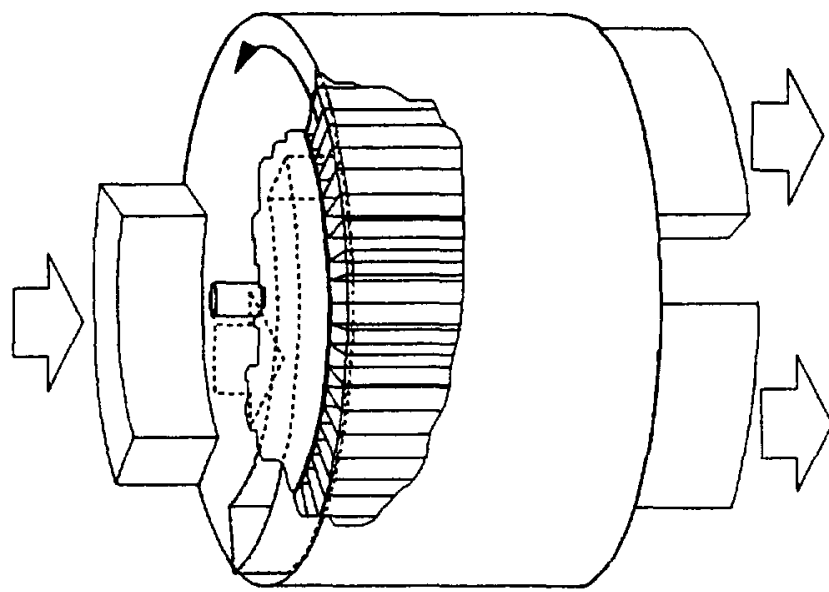

Figure 1 Wave Rotor Schematic
In order to correctly design or predict the performance of a wave rotor it is necessary to account not only for the unsteady wave processes which are usually assumed to govern the machine but also for some of the major loss mechanisms that exist. These include leakage from the ends of the wave rotor passages to the cavity in which they rotate (Figure 2), viscous losses, heat transfer from the passage walls to the gas, and losses induced by the finite opening time of the tubes as they enter and leave the ports. It has been consistently shown in experiments ${ }^{7,8,9}$ that machines designed without these losses considered, perform substantially worse than the idealized predictions. Several multidimensional numerical studies ${ }^{10,11}$ are presently being conducted in order to examine the complex fluid mechanics associated with these as well as other losses. An effort is underway by the author however, to develop a numerical model which can appraise these major losses, but which is simple enough to be used for rapid, general design and analysis. The following paper will provide a description of this model as well as comparisons between the model predictions and three wave rotor experiments that have been/are being performed ${ }^{7,8,9}$. It is noted that some of the model description has been reported previously ${ }^{12}$ and as such will be suitably abbreviated here.

\subsection{Model Description}

The model numerically integrates the equations of motion in a single passage as it rotates past the various ports and walls that comprise the ends of the wave rotor. These ports (and walls) establish the boundary conditions for the governing equations in the passage. Ports are specified by their angular location relative to some fixed point on the wave rotor, and by a representative pressure and temperature. Up to six ports may be specified on the present model (three per side). With each time step the passage advances an angular distance specified by the angular velocity. If the flow is into the passage, the pressure and temperature are interpreted as stagnation values. If the flow is out of the passage, only the port pressure is required, and it is interpreted as a static value. Determination of the direction of the flow at each time step is somewhat difficult and is discussed in section 2.2 as well as in references 6 and 12 .

The governing equations may be written as:

\footnotetext{
Member AIAA
}

Conyright 1993 by the American Institute of Aeronsutics and Astronautics, Ioc. No copyright is asserted in the United States under Tite 17, U.S. Code. The U.S. Govermment has royaliy-free license to exercise all rights under the copyright claimed berein for Governmental purposes. All other rights are reseryed by the copyright owner. 


$$
\frac{\partial \underline{w}}{\partial t}+\frac{\partial E(w)}{\partial x}=S(w)
$$

where the vectors $\underline{w}$ and $E$ have the respective perfect gas forms:

$$
\begin{aligned}
& \underline{w}=\left[\begin{array}{l}
\rho \\
\rho u \\
\left.\frac{p}{\gamma(\gamma-1)}+\frac{\rho u^{2}}{2}\right)
\end{array}\right] \\
& \underline{F}=\left[\begin{array}{l}
\rho u \\
\frac{p}{\gamma}+p u^{2} \\
u\left(\frac{p}{(\gamma-1)}+\frac{\rho u^{2}}{2}\right)
\end{array}\right] .
\end{aligned}
$$

Here, $\gamma$ is the ratio of specific heats. These equations have been nondimensionalized using a reference state $p^{*}, \rho^{*}$, and $a^{*}$, where $a^{*}$ is the speed of sound. The distance has been scaled by the passage length, $L$, and the time has been scaled using the wave transit time, $\frac{L}{a^{*}}$. The form of the source vector $\underline{S}(\underline{w})$ will be discussed in section 2.1 . Equation 1 is integrated numerically using the following technique:

$$
\underline{w}_{i}^{n+1}=\underline{w}_{i}^{n}-\left(f_{i+1 / 2}^{n}-f_{i-1 / 2}^{n}\right) \frac{\Delta t}{\Delta x}+\underline{s}_{i}^{n} \Delta t
$$

where the numerical flux estimate $\mathrm{f}_{1+1 / 2}^{\mathrm{n}}$ is

$$
\begin{aligned}
\underline{f}_{i+12}^{n}=\frac{F_{i+1}^{n}+E_{i}^{n}}{2} & -\frac{1}{2} \Phi_{i+1 / 2}^{R e c} \\
& +\frac{\Delta t}{4}\left([A]_{i+1}^{n} \frac{S}{i+1}^{n}-[A]_{i}^{n} \frac{S}{i}^{n}\right)
\end{aligned}
$$

and the numerical source $\frac{s^{n}}{1}$ is

$$
\underline{S}_{i}^{n}=\frac{1}{2}\left(3 \underline{S}_{i}^{n}-S_{i}^{n-1}\right)
$$

The term $\phi^{\text {Roc }}$ in equation 5 refers to the flux limited dissipation based on Roe's ${ }^{13}$ approximate Riemann solver for equation 1 without a source vector. The matrix $[A]$ is the Jacobian of the flux vector $E$. The superscript $n$ indicates the discrete temporal index $n \Delta$, and the subscript $i$ indicates the spatial index $i \Delta x$. This scheme has the advantage of being formally second order accurate in time and space when the flow is smooth yet maintaining the high resolution of Roe's method in the vicinity of shock waves. Furthermore, as the source strength approaches zero, the scheme becomes monotonic, which is physically correct. Equation 4 is also conservative in the sense that when summed over the index $i$, an approximation to integration, the only changes to the conserved vector arise from the fluxes at the ends and the source terms (this is not the case for the scheme described in reference 10 ).

\subsection{Source Terms}

There are three effects presently modelled which contribute to the source vector. These are: viscous effects, heat transfer from the passage walls to the working fluid, and leakage from the passage to the wave rotor cavity. These effects are illustrated in Figure 2 and will be discussed below.

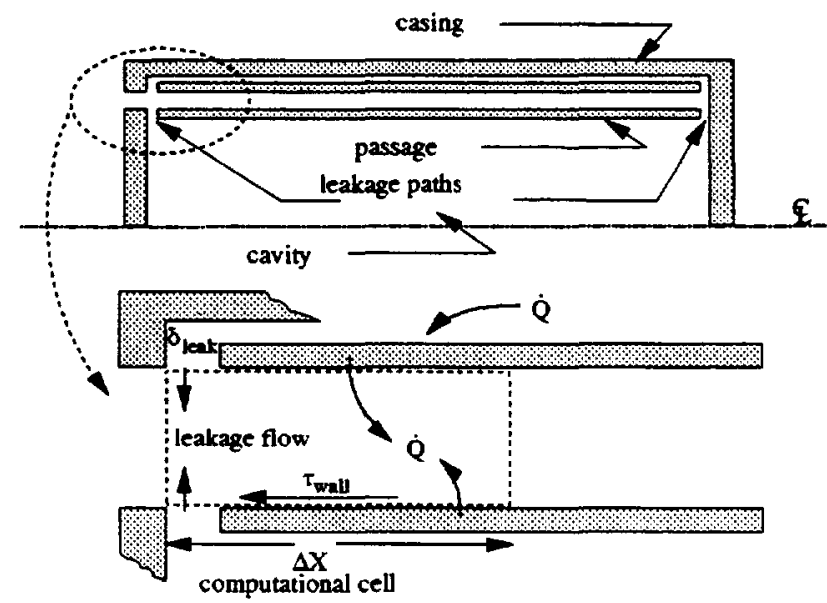

Figure 2 Source Term Contributions

\subsubsection{Viscous Source Term}

For a one dimensional model, viscous effects are manifested as a wall shear stress or skin friction factor. An estimate has been obtained in the present model by assuming that the friction factor is some function of the local Reynolds number in the computational cell. The relevant length scale for the unsteady flow in the passage is the height of the boundary layer $\delta$. This height may be estimated using the analogy of a suddenly accelerated plate (i.e. Stokes first problem) as

$$
\delta=\sqrt{\frac{v L}{a^{*}}}
$$

where $v^{*}$ is the kinematic viscosity at the reference state (viscosity is assumed constant). Although many possibilities exist for the functionality of the friction factor, the present model assumes that it is proportional to the Reynolds number raised to some power, i.e.

$$
c_{f} \equiv \frac{\tau_{\text {wall }}}{\rho u^{2}}=\alpha \operatorname{Re}_{\delta}^{-j} .
$$


From the data collected thus far, the best value for $j$ appears to be $1 / 2$. Thus, the non-dimensional viscous source term of equation 1 takes the form

$$
\begin{aligned}
& s_{2}=\sigma_{2} u \sqrt{\rho p d \mid} \\
& \sigma_{2} \equiv-4 \alpha\left(\frac{L}{D_{b}}\right)^{1 / 2}\left(\frac{\sqrt{\frac{v^{\top} \mathrm{L}}{a^{*}}}}{D_{b}}\right)^{1 / 2},
\end{aligned}
$$

where $D_{b}$ is the passage hydraulic diameter. The values of $\alpha$ for the three experiments studied are listed in Table 1. These were found to yield the best match to the data. It is encouraging to note that they are all nearly the same.

\subsubsection{Heat Transfer Source Term}

Heat transfer is assumed to occur only between the working fluid and the upper and lower walls of the passage. No passage to passage heat transfer is accounted for. It is also assumed that no conduction of heat occurs along the passage walls (i.e. the $x$ direction). The Reynold-Colburn analogy ${ }^{14}$ is used to calculate the heat transfer coefficient from the skin friction coefficient of equation 8 . The resulting source term is

$$
\begin{aligned}
& s_{3}^{\mathrm{m}}=\sigma_{3}^{\mathrm{ht}} \sqrt{\rho \mid \mathrm{u}}\left(\mathrm{T}-\mathrm{T}_{\text {wall }}\right) \\
& \sigma_{3}^{\mathrm{m}} \equiv \frac{\sigma_{2}}{\gamma-1}\left(\frac{\mathrm{D}_{\mathrm{b}}}{2 \mathrm{~h}}\right) \operatorname{Pr}^{-2 / 3},
\end{aligned}
$$

where Pr is the Prandtl number, $h$ is the passage height, and $T$ and $T_{\text {wall }}$ are the gas and wall temperatures for the computational cell scaled by the reference temperature $T^{*}$.

A lumped capacitance technique is used to track the temperature of the wall. Refering to Figure 3, the governing equation for any discreet section may be written in nondimensional form as

$$
\begin{aligned}
& \frac{\mathrm{dT}_{\text {wall }}}{\mathrm{dt}}=\phi_{1}\left(\mathrm{~T}_{\text {wal }}-\mathrm{T}\right)+\phi_{2}\left(\mathrm{~T}_{\mathrm{cav}}-\mathrm{T}_{\text {wall }}\right) \\
& \phi_{1}=\frac{\gamma-1}{2} \sigma_{3}^{\text {hat }}\left(\frac{\mathrm{h}}{\delta_{\text {wall }}}\right)\left(\frac{1}{\rho_{\text {wall }}}\right)\left(\frac{c_{\mathrm{p}}}{c_{\text {wall }}}\right) \\
& \phi_{2}=0.02 \operatorname{Pr}^{-0.4}\left(\frac{\mathrm{L}}{\delta_{\text {wall }}}\right)\left(\frac{c_{\mathrm{p}}}{\mathrm{c}_{\text {wall }}}\right)\left(\frac{\mathrm{a} \cdot \mathrm{R}}{v^{*}}\right)^{-0.2} \\
& \times\left(\frac{1}{\rho_{\text {wall }}}\right)\left(\frac{\rho_{\text {cav }} \omega \mathrm{R}}{\mathrm{a}^{*}}\right)^{0.8} .
\end{aligned}
$$

Here, $\delta_{\text {wall }}, c_{\text {wall }}$, and $\rho_{\text {wall }}$ are the wall thickness, specific heat and nondimensional density, respectively; $c_{p}$ is the gas specific heat at constant pressure, $\mathbf{R}$ is the rotor radius, $\rho_{\text {cav }}$ is the nondimensional cavity density, and $\omega$ is the rotor speed. The coefficients $\phi_{1}$ and $\phi_{2}$ are the product of the Fourier and Biot moduli ${ }^{14}$ for the inner and outer surface of the wall, respectively. The heat transfer coefficient in $\phi_{1}$ is the same as that in equation 10 , while the heat transfer coefficient in $\phi_{2}$ was derived from a correlation for steady turbulent flow over a flat plate ${ }^{15}$ with the flat plate length replaced with the rotor circumference. Analysis has indicated that the time constants associated with transients in the wall temperature and those in the cavity (Figure 2) are much larger than the wave transit time or even the time for one complete wave cycle. Thus the wall temperature distribution (and the state of the cavity) is assumed constant for one wave cycle and equation 11 is integrated using simple Euler integration as

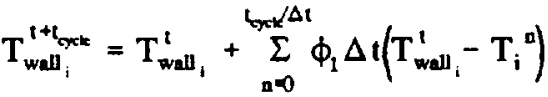

$$
\begin{aligned}
& +\phi_{2} t_{\text {cyde }}\left(T_{\text {cav }}^{\prime}-T_{\text {wall }}^{\prime}\right) \text {. }
\end{aligned}
$$

In practice (for steady state results) a much smaller wall thickness than the actual value is used in $\phi_{1}$ and $\phi_{2}$ (about 1/100th). This speeds convergence of the wall temperature distribution.

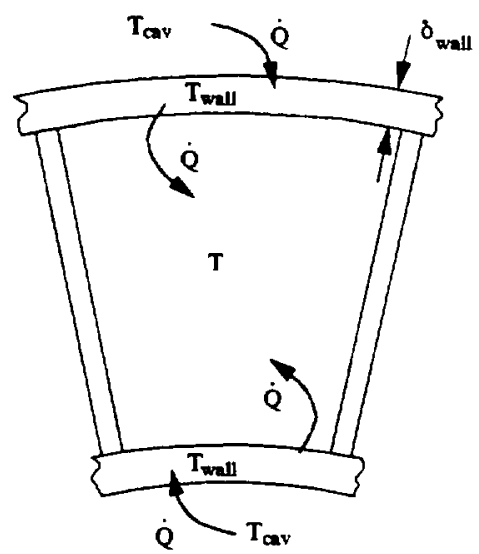

Figure 3 Wall Heat Path Schematic

\subsubsection{Leakage Source Term}

Since leakage occurs only at the ends of the wave rotor passage, the leakage source terms are only added to the first and last computational cells of the model (not the image cells used for implementing boundary conditions). Only leakage to and from the cavity is modelled. Leakage from one passage to another is neglected. The leakage at each end is assumed to occur in the manner of an isentropic, steady flow orifice which has an area equal to twice the product of the leakage gap $\delta_{\text {leak }}$ and the passage width $b$. The leakage affects both the continuity and energy equations of the vector equation 1 . The 
nondimensional form of these sources may be written as

$$
\begin{aligned}
& s_{1}^{\prime}=\sigma_{1} \sqrt{p \rho} f\left(\frac{p_{\text {cav }}}{p}\right) \\
& \sigma_{1}^{\prime} \equiv-C_{D} \sqrt{\frac{2}{\gamma-1}}\left(\frac{\delta_{\text {leak }}}{h \Delta x}\right),
\end{aligned}
$$

and

$$
\begin{aligned}
& s_{3}^{\prime}=\sigma_{3} T_{0} \sqrt{p \rho} f\left(\frac{p_{c a v}}{p}\right) \\
& \sigma_{3} \equiv \frac{\sigma_{1}^{\prime}}{\gamma-1} .
\end{aligned}
$$

Here, $T_{0}$ is the nondimensional stagnation temperature, and $C_{D}$ is the discharge coefficient. The function $f$ is St. Venant's orifice equation ${ }^{16}$ defined by

$$
\begin{aligned}
& f= \sqrt{\left(\frac{p_{c a v}}{p}\right)^{\frac{2}{\gamma}}-\left(\frac{p_{c a v}}{p}\right)^{\frac{\gamma+1}{\gamma}}} ; \frac{p_{c a v}}{p}>\frac{2}{\gamma+1} \text { (15) } \\
& \sqrt{\left(\frac{2}{\gamma+1}\right)^{\frac{2}{\gamma-1}}-\left(\frac{2}{\gamma+1}\right)^{\frac{\gamma+1}{\gamma-1}}} ; \frac{p_{c a v}}{p}<\frac{2}{\gamma+1} .
\end{aligned}
$$

If the cavity pressure is greater than cell pressure then the pressure ratio in equation 15 is inverted, the sign of $f$ changes, and $p, p, T_{0}$ become those of the cavity. Note that those cells with leakage have two contributions to the energy equation source term, one from equation 10 and one from 14.

Like the wall temperatures, the cavity state is assumed constant over the period of one cycle and is updated using Euler integration of the continuity and energy equations written as

$$
\begin{aligned}
& \rho_{\text {cav }}^{t+h_{\text {ret }}}=\rho_{\text {cav }}^{l}-\left(\frac{R h L}{V_{\text {cav }}}\right) \Delta x \Delta t \theta_{p} \\
& \left.\times \sum_{n=0}^{b \times d}\left[s_{1}\right]_{\text {left }}^{\prime}+\left[s_{1}^{\prime}\right]_{\text {ighat }}^{n}\right)
\end{aligned}
$$

$$
\begin{aligned}
& p_{c a v}^{t+t c o v e}=p_{c a v}^{t}-\left(\frac{R h L}{V_{c a v}}\right) \Delta \times \theta_{p}
\end{aligned}
$$

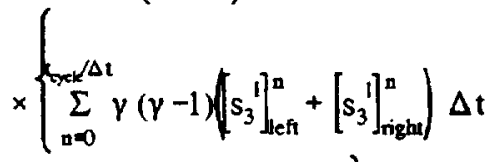

$$
\begin{aligned}
& \left.-t_{\text {cyde }} \phi_{3} \sum_{i=0}^{N}\left(T_{\text {wall }}-T_{\text {cav }}\right)\right\} \text {, }
\end{aligned}
$$

where

$$
\begin{aligned}
\phi_{3}=0.04 \operatorname{Pr}^{-0.4} \gamma\left(\frac{\mathrm{L}}{\mathrm{h}}\right)\left(\frac{\mathrm{c}_{\mathrm{p}}}{\mathrm{c}_{\text {wall }}}\right)\left(\frac{\mathrm{a} \mathrm{R}}{v^{*}}\right)^{-0.2} \\
\times\left(\frac{1}{\rho_{\text {wall }}}\right)\left(\frac{\rho_{\mathrm{cav}} \omega \mathrm{R}}{\mathrm{a}^{*}}\right)^{0.8},
\end{aligned}
$$

$\theta_{p}$ is the angular passage width, $N$ is the number of computational cells, and $V_{\text {cav }}$ is the cavity volume.

\subsection{Boundary Conditions: Flow Direction and Finite Opening Time}

The implementation of appropriate boundary conditions has been discussed in detail in references 6 and 12 . Briefly, there are two major complications to be dealt with. The first is that the wave rotor model must be able to calculate the flow field in the passage for any specified set of ports and port conditions. This means that it must be capable of marching in time regardless of the direction of the flows at the ends. The second complication of applying boundary conditions arises from the fact that as a passage enters or leaves the vicinity of a port, a period of time exists when the passage end is only partially open. This is shown in Figure 4 for the case of inflow. This effect is sometimes referred to as finite opening time and can substantially influence the dominant wave speeds if the time required to fully open the passage to the port region is of the same order as the characteristic wave transit time.

Considering first the flow direction problem, hyperbolic equations such as 1 have very different boundary requirements for inflow and outflow. These requirements relate to the characteristic, or directional nature of the governing equations. At any boundary, some flow information must come from outside the computing domain and some must be extracted from within. If, for instance, the flow is out of the passage, then only one piece of outside information may be supplied. Typically this is the static pressure. If the flow is inward, then two pieces of outside data are needed. If inflow boundary conditions are specified for a flow that is actually outward then the problem is ill-posed and errors (usually 
catastrophic) result. At each time step then, the model must somehow "look ahead", determine the direction of the flow, and supply the requisite information. In practice, this is achieved as follows. At any port, the flow is assumed to be outward and the specified pressure is interpreted to be static. This information, together with the state of the interior computational cell adjacent to the boundary is enough to solve for the velocity and density across the single wave which assumed to be travelling into the computing space (i.e. at the boundary). If the velocity is indeed outward, then the problem is solved and the calculated pressure, density, and velocity are assigned to the image cell (a fictitious computational cell outside the computing domain). If the calculated velocity is inward, then the initial assumption was incorrect. At this point the problem is restarted assuming inflow and with the specified temperature and pressure interpreted as stagnation values. Assuming the flow in the port is isentropic and steady, the port stagnation conditions and the adjacent interior computational cell state (and a Mach number if the flow is supersonic) uniquely determine the two waves which travel into the computing space, and thus the state of the image cell.

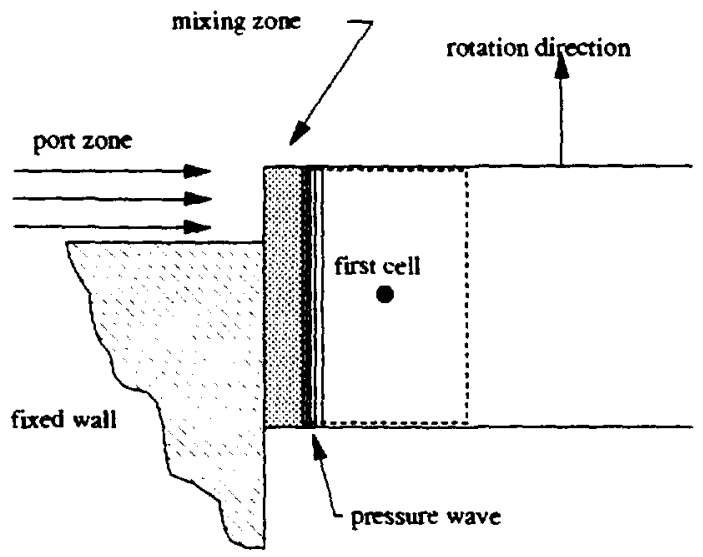

Figure 4 Finite Opening Time

The finite opening time effect is accounted for in the model as follows. For inflow, the port zone is again assumed isentropic and steady with specified stagnation conditions. It is connected to a fictitious steady mixing zone by way of a converging nozzle with throat area equal to that of the partially open end of the passage. In the mixing zone the fluid is assumed to expand to the full area of the passage and to a uniform state. Adjacent to the mixing zone is the first interior computing cell in which the state is known. A guess is made for the exit pressure of the "nozzle" throat. This uniquely determines the state of the fluid at the exit of the mixing zone. The pressure at the end of the mixing zone, together with the state of the first computing cell determine the velocity across the two characteristic waves that are travelling into the passage. This velocity must match that at the end of the mixing zone. If it does not, then a new guess must be made for the throat exit pressure. This process is repeated iteratively until the velocities match. At this point the computed pressure, density, and velocity at the exit of the mixing zone are assigned to the image cell. For outflow the specified port pressure is assumed static. Now the mixing zone of Figure 4 is replaced by a fictitious steady isentropic nozzle which converges from the passage area to the partially opened area. A guess is made of the pressure at the entrance to the nozzle. This pressure and the conditions of the first cell determine the state across the single characteristic wave travelling into the passage and thus the mass flux out of the passage. A second mass flux can be computed from this state, the port static pressure, and the throat area of the nozzle. These two mass flows must agree or the initial guess at the upstream nozzle pressure was incorrect. Again the process is iterative. Upon convergence, the state at the nozzle entrance is assigned to the image cell.

\subsection{Experimental Comparison}

There are three wave rotor experiments with which the numerical model has been compared. Two of them were performed some time ago in the 1960 's, one by J.A.C Kentfield, and the other by the General Electric Company $^{8}$. The third experiment is presently ongoing at the NASA Lewis Research Center?. Of the two earlier experiments, Kentfield's was a so-called divider cycle in which air enters the rotor at some intermediate pressure, is split, and exits through two ports. In one port the stagnation pressure is higher than the entering stream and in the other it is lower. The G.E. experiment was an actual wave engine (i.e. wave rotor with heat addition). Here, air enters the rotor at a relatively low pressure and temperature, is compressed, and exits the rotor. It is then heated by an external combustor and sent back into the rotor where it is expanded and exits at a stagnation pressure and temperature above the entering cool stream. The NASA experiment is also a divider cycle; however, the details of the wave timing are quite different from Kentfield's.

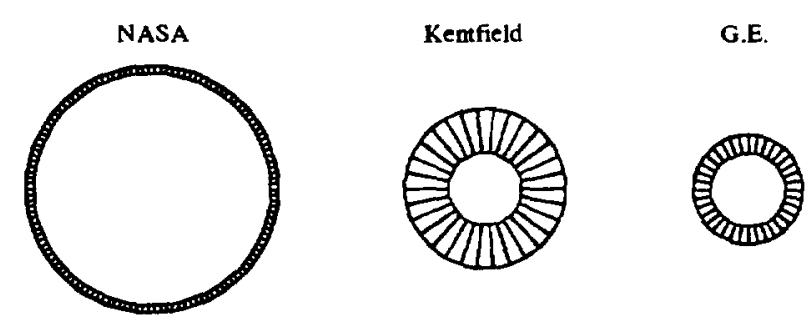

Figure 5 Experimental Rotor Geometries

The relative rotor geometries and parameters for the three 
experiments are shown in Figure 5 and in Table 1, respectively. A quick glance at Figure 5 shows the large differences in the passage cross sections for the three experiments.

For any of these cycles (port timing and boundary conditions) the model is run continuously until the wave pattern in the passage repeats itself, the net mass flow rate through all of the ports is zero, the cavity states are constant, and the wall temperature distribution is constant. Global quantities such as mass flow and outflow port stagnation values were obtained from the model by numerically integrating the mass momentum and energy flux in the image cells as they pass through the port areas. A constant area mixing calculation is then used to obtain averaged quantities ${ }^{6}$.

\begin{tabular}{|c|c|c|c|}
\hline & $\overline{\text { NASA }}$ & Kentfield & G.E. \\
\hline Length, L & $18.0 \mathrm{in.}$ & 11.0 & 12.0 \\
\hline Mean Radius, $\mathbf{R}$ & 6.0 in. & 2.9 & 2.3 \\
\hline $\begin{array}{l}\text { Number of } \\
\text { Passages }\end{array}$ & 130 & 30 & 36 \\
\hline Passage Height, h & 0.4 in. & 2.2 & 0.91 \\
\hline Leakage Gap, $\delta_{\text {leak }}$ & variable & 0.007 in & 0.025 \\
\hline Speed & $-4000 \mathrm{rpm}$ & 6000 & 19,000 \\
\hline $\begin{array}{l}\text { Inlet Total } \\
\text { Pressure }\end{array}$ & $\sim 30$ psia & variable & $\sim 15$ \\
\hline Inlet Total Temp. & $-600 \mathrm{R}$. & 555 & 510 \\
\hline \multirow[b]{2}{*}{$\begin{array}{l}\text { Exit Static } \\
\text { Pressure }\end{array}$} & $\begin{array}{l}\text { low: } \\
\text { variable }\end{array}$ & $\begin{array}{l}\text { low: } \\
\sim 15 \text { psia }\end{array}$ & \multirow[t]{2}{*}{-15} \\
\hline & $\begin{array}{l}\text { high: } \\
\text { variable }\end{array}$ & $\begin{array}{l}\text { high: } \\
\text { variable }\end{array}$ & \\
\hline Cycles/rev. & 1 & 3 & 1 \\
\hline $\begin{array}{l}\text { Discharge } \\
\text { Coefficient, } C_{D} \\
\text { eqn } 13\end{array}$ & .5 & .5 & .47 \\
\hline$\alpha$ eqn. 9 & .1374 & .1266 & .1319 \\
\hline
\end{tabular}

Table 3.0.1 Experimental Parameters

\section{LNASA Divider Cycle}

This experiment is highly instrumented, and a significant amount of data may be collected for comparison purposes. The rotor was specifically designed to parametrically study the loss mechanisms dealt with in this paper. At the time of this writing, very few of the planned experimental runs have been performed. Nevertheless, the data available, combined with that of the other experiments to be compared provide a fairly complete validation of the model.

For each experimental run all of the data necessary to the model was available. The static pressures needed for the model outlet ports were obtained using an average of 10 evenly spaced static taps in the ports of the experiment.

For the configuration described in Table 1 two experimental runs were compared corresponding to two different settings of the leakage gap, $\delta_{\text {leak }}$. These settings are shown in Table 2. For each run, the ratio of high pressure port mass flow to total mass flow, $\beta$, was held at a constant nominal value of 0.37 . The model parameters $\alpha$ and $C_{D}$ were found by matching both $\beta$ and the cavity pressure to the experiment at two test points of the highleakage gap run corresponding to the highest and lowest values of mass flow. It is interesting to note that the values of these two parameters varied little between the NASA, Kentfield, and G.E. experiments.

\begin{tabular}{|l|l|l|}
\hline$\delta_{\text {leak }}$ in. & High Leakage & Low Leakage \\
\hline Left Wall & 0.025 & 0.005 \\
\hline Right Wall & 0.014 & 0.005 \\
\hline Medium Port & 0.010 & 0.005 \\
\hline Low Port & 0.010 & 0.005 \\
\hline High Port & 0.010 & 0.005 \\
\hline
\end{tabular}

Table 3.1.1 Leakage Gaps of NASA Experiment
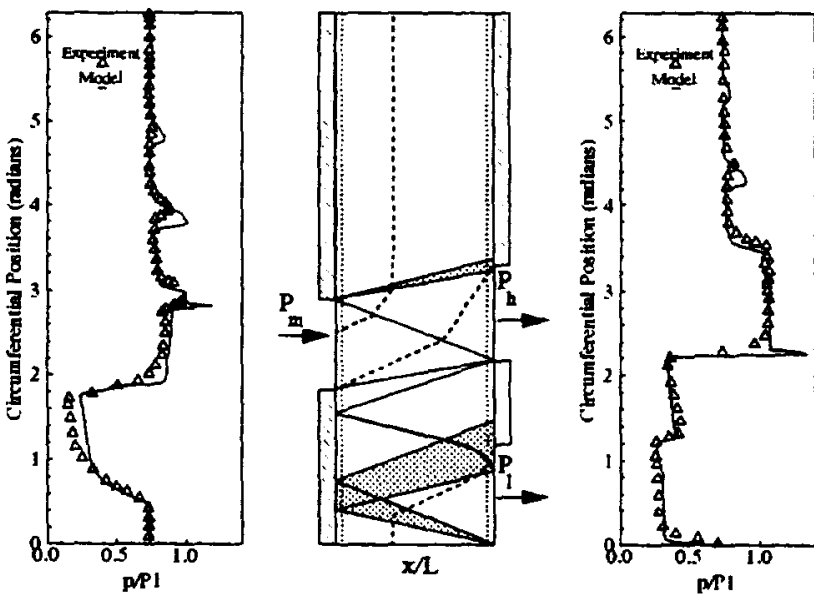

Figure 6 Pressure Trace of NASA Experiment

Figure 6 shows a comparison between model and experiment of the pressure at two axial locations on-board the passage as it moves through the cycle at one test point (maximum mass flow) of the high-leakage run. Solid lines represent the calculated pressure, triangles represent experimental data which was digitized from an oscillogram photograph. The wave diagram in the center of the figure 
shows schematically the intended cycle. Also shown in this diagram as dotted lines are the locations of the pressure transducers used to collect the data $(2.5 \%$ from each end of the passage). The subscripts $m, h$, and $l$ on the diagram refer to the medium (inlet), high, and low pressure ports respectively. The dashed line represents a hypothetical particle path which separates the compressed from the expanded gas. The data has been normalized by the inlet stagnation pressure, $\mathrm{P} 1$, of one particular test run which had a value of 30.25 psia. The agreement appears quite good with the only significant discrepancy being on the left side of the rotor in the vicinity of the initial expansion (1-2 radians). This region is where the pressure in the device is the lowest and the leakage gap the largest. Thus, the error may reflect the rather crude nature of the leakage model. This explanation has been verified by comparisons of the low-leakage gap case (not shown here) which do not exhibit the discrepancy. It is reassuring that the model nicely tracked the weak waves which remain in the top portion of the cycle due to mis-timed ports. Although space does not permit it, it is noted that plots similar to Figure 6 were generated at other test points with equally good results.

Figure 7 shows a comparison of the high versus low stagnation pressure for the test runs. The experimental stagnation values were obtained by a simple average of 4 stagnation probes placed in each port. In the figure, all of the data has been normalized by the inlet stagnation pressure. The model agreement with the data is again quite good.

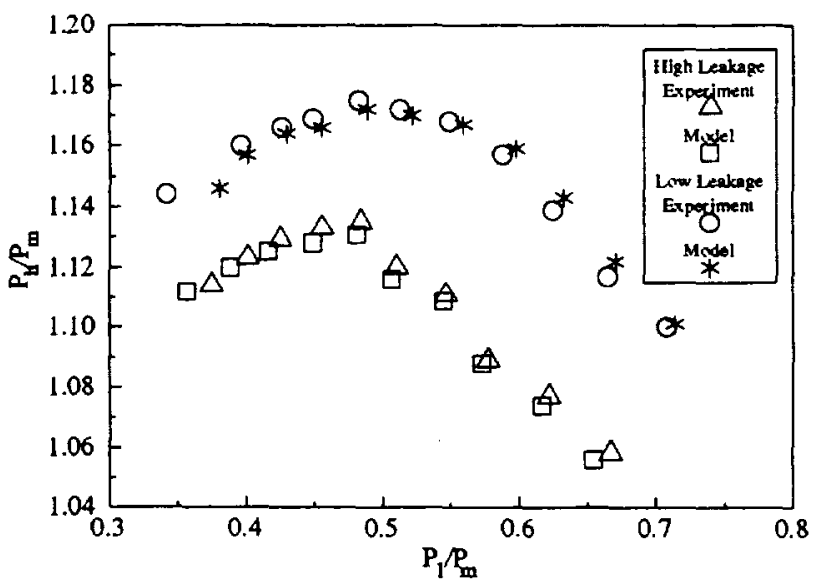

Figure 7 NASA Experiment High Versus Low Pressure

Figure 8 shows a comparison of the mass flow through the device as a function of the pressure ratio $P_{p} P_{m}$ for the same test runs as the previous figure. The model and experiment agree well for the high-leakage case except at the lowest values of pressure ratio. For the high-leakage test points, the predicted mass flow was an average of $7 \%$ above the measured. For the low leakage case the discrepancy was larger at an average value of $17 \%$. Several explanations may account for the general tendency of the model to overpredict the mass flow. First, the walls of the passages have a finite thickness which creates a certain degree of blockage. This is not accounted for by the model. In the NASA experiment the passage walls are approximately $16 \%$ of the passage width.

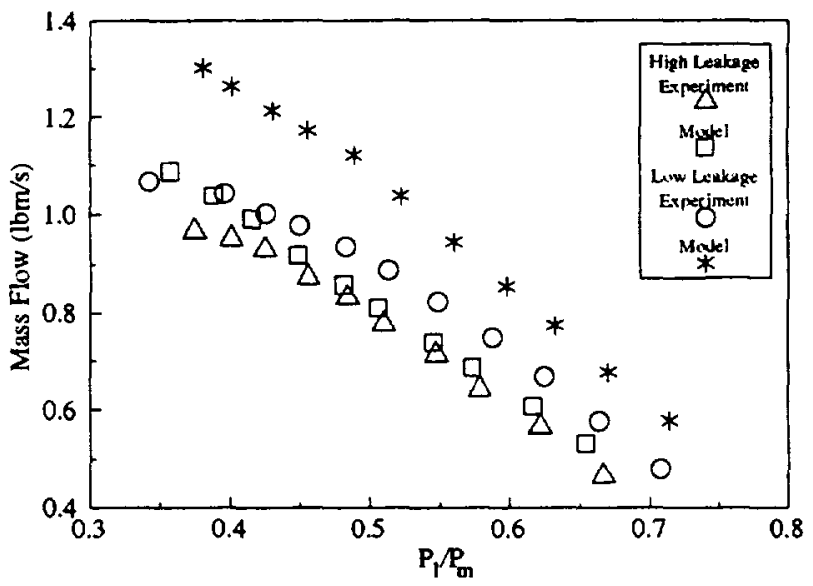

Figure 8 NASA Experiment Mass Flow Versus $P_{\mathrm{f}} P_{m}$

A second possible reason for the mass flow error may be that the ports of the NASA experiment are angled incorrectly to account for the circumferential velocity component of the passages. This is illustrated schematically in Figure 9 for the extreme case of ports arranged perpendicular to the rotor face (Kentfield's experiment). The port flow approaches the passages at a high relative angle of attack. The flow must be turned in order to align with the passages and the result is a series of separation regions in all of the passages which are exposed to the port. The separation adds a degree of blockage in the device which the model does not account for.

As for the difference in error between the high and low leakage runs, this may just be the result of improperly chosen values of $\alpha$ and $C_{D}$ which the NASA experiment is quite sensitive to.

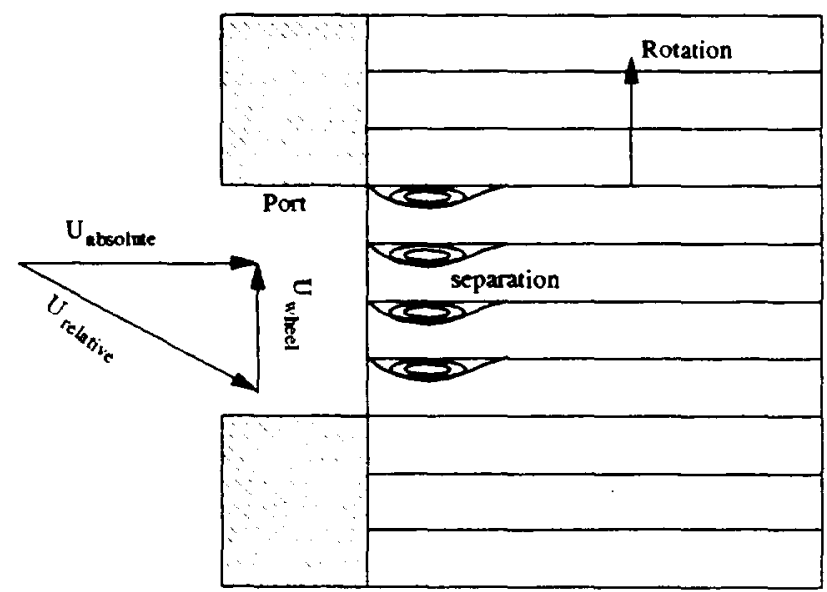

Figure 9 Separation Blockage Schematic

Figure 10 compares the model with experimental values of the mass flow parameter, $\beta$ as a function of $P, P_{m}$ for the 
two leakage gap cases. Here, larger errors appear to exist. The shape of these curves can be affected strongly by the power of the skin friction exponent $j$ in equation 8 . It is believed, therefore, that the discrepancy reflects the simplicity of the friction model. It is noted however, that the scale in this figure is quite expanded and that the average $\beta$ from the high leakage experiment is 0.372 while the model predicts 0.348 which is only a $7 \%$ error. For the low leakage cases the respective averages are 0.371 and 0.351 which is also only a $7 \%$ difference.

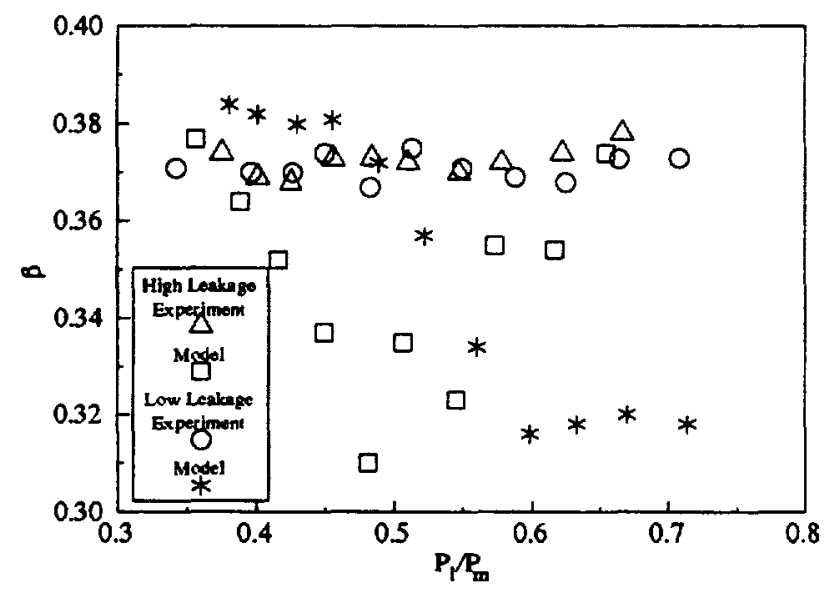

Figure 10 NASA Experiment $\beta$ Versus $\mathbf{P}_{\mathbf{f}} \mathbf{P}_{\mathrm{m}}$

Finally Figure 11 shows three sets of pressure contours in the wave rotor passage which were calculated by the model. All of the contours used the same boundary conditions from a single test point. This was the same test point used in Figure 6. The left most contour includes all of the loss mechanisms described above (nominal). The center contour includes only friction and heat transfer (no leakage) and the right most contour includes only the finite opening time effect (no leakage, inviscid). These side by side contours clearly illustrate the effect that the losses have on the wave pattern. Comparing first the Nominal and No Leakage contours, it appears that leakage has the effect of damping any waves that remain at the end of the cycle. This can be seen by examining the upper portion of the two contours. The effect of leakage on wave timing may be seen by noting that in the Nominal case, the shock separating the high pressure port from the inlet port $(\theta=2.24-3.0$ radians) arrives early, whereas in the no leakage case it arrives at the proper time. Comparing the No Leakage contour to the No Leakage, Inviscid contour illustrates the substantial effect which friction has on the wave timing. In particular, the waves in the inviscid calculation are quite mis-timed in the high pressure region of the cycle. The predicted mass flows from the no leakage and no leakage, inviscid calculations were respectively $21 \%$ and $54 \%$ above the base calculation with all of the losses modelled. The values of $\beta$ were respectively 0.44 and 0.72 as compared with 0.37 for the base case.
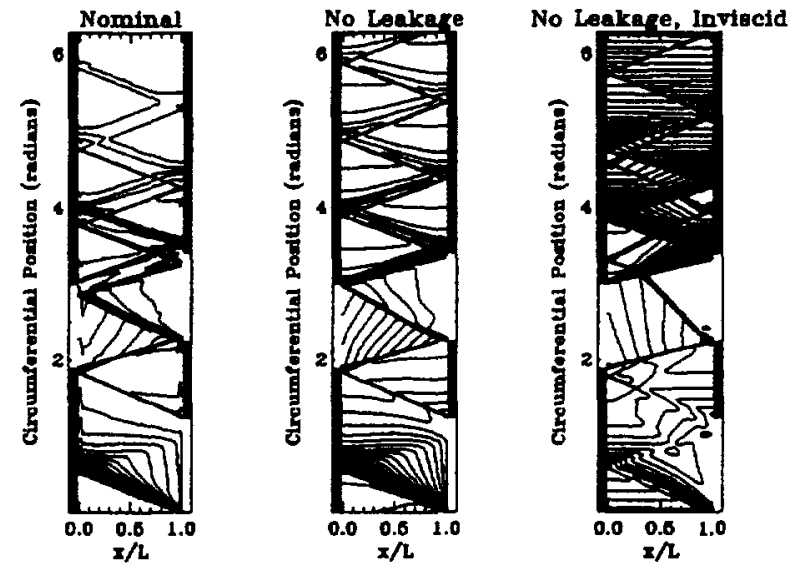

Figure 11 Pressure Contours for One Test Point

\section{Kentfield Divider Cycle}

As mentioned, Kentfield's cycle was also a pressure divider, however, the geometry of the rotor was quite different from the NASA experiment (Table 3.0.1). In particular, the ratio $\delta_{\text {leak }} / h=0.0032$ is very small and the angular passage width, $\theta_{p}$ is large compared to the width of a port. Furthermore, the wave diagram, which is shown schematically in Figure 12 was also quite different. Note that the wave diagram shown represents only $1 / 3$ of a revolution of the rotor.

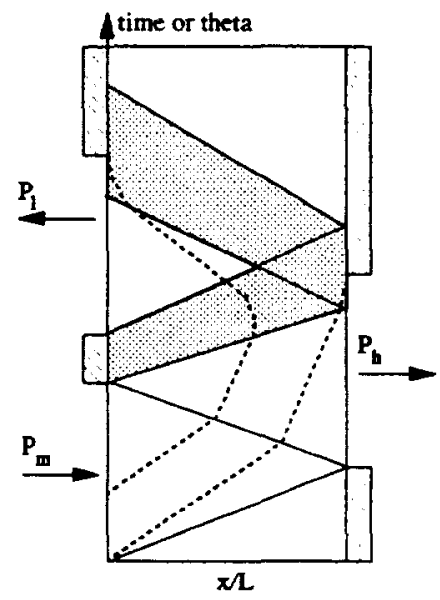

Figure 12 Kentfield Divider Wave Diagram

Much less data is available from the Kentfield experiment than from the NASA rig. The comparison of model versus experiment may be summarized on the single plot shown in Figure 13. Like Figure 7, this is a plot of high versus low stagnation pressure, normalized by the inlet stagnation pressure. In this plot however, there are several families of curves representing various values of the mass flow parameter $\beta$. The symbols represent results from the model while the various lines represent experimental data. In the experiment, the low pressure outlet port was vented through a flow meter to the atmosphere. Kentfield indicated in his thesis that the static pressure in this port 
remained nearly constant throughout the testing at approximately atmospheric pressure. Therefore, for the numerical experiment, the low pressure port was maintained at this value. The data points were obtained by adjusting the inlet stagnation, and high pressure outlet static pressures until the desired value of $\beta$ was obtained. The inlet stagnation temperature and rotational speed were held at the constant values shown in Table 3.0.1. The comparison between the experimental and model data is good. Note, in particular, that as the low pressure is decreased more and more, indicating increased work extraction from the flow, the subsequent gain in the high pressure, indicating work done on the flow, is less and less (i.e. the curves "flatten" as one moves to the left). This trend appears to be a result of the losses, for it is not seen when they are neglected ${ }^{6}$. The fact that the model tracks this trend well for all values of $\beta$ is particularly encouraging. Two dashed lines are also shown on this plot representing calculated and measured constant inlet Mach number lines for $M=0.3$. For a given set of inlet conditions, the Mach number may be considered a measure of the mass flow rate. Thus, it is seen from the plot that the model again overpredicts the device throughflow.

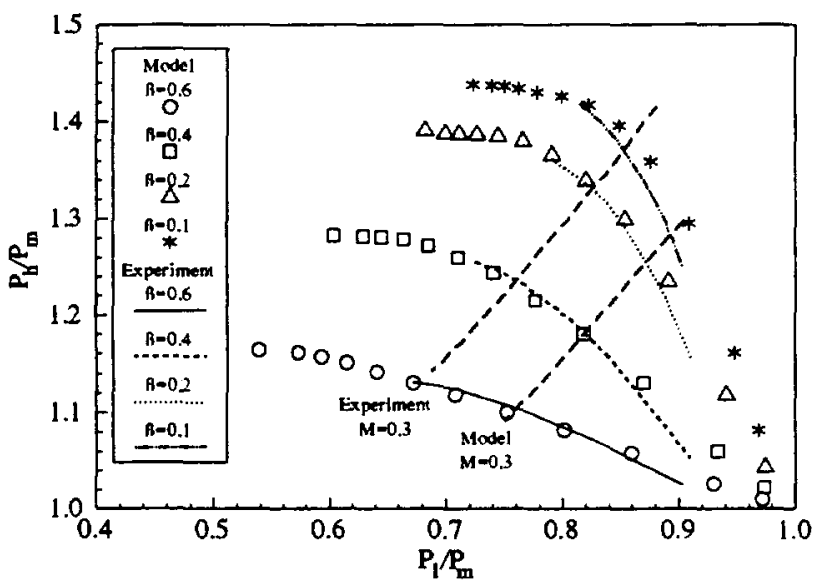

Figure 13 Kentfield's Performance Map

\subsection{GeneraL Electric Topping Cycle}

The information on the General Electric experiment came from three quarterly reports ${ }^{7}$ which documented the program. None of the documented tests contained complete information regarding the results. As a consequence, some of the information supplied to the model was inferred by the author of the present paper. This will be explained below. It is noted however, that the General Electric experiment was a true wave engine and thus, represents an important test point for the model.

Figure 14 shows the proposed wave diagram and nomenclature for the cycle. The experimental data did not include stagnation pressures for the delivery port (the port coming from the burner) so the model was modified to include a combustor. As with the rotor cavity, the combustor was treated as a single lumped capacitance system which was updated once per rotor revolution or cycle. The governing equations may be written in nondimensional form as

$$
\begin{aligned}
& \rho_{\text {comb. }}^{i+b_{\text {cat }}}=\rho_{\text {comb. }}^{1}+\left(\frac{R h L}{V_{\text {comb. }}}\right) \Delta t \theta_{\text {cycle }}
\end{aligned}
$$

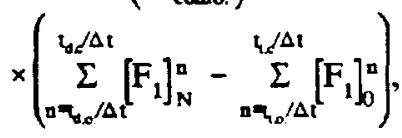

$$
\begin{aligned}
& \mathrm{p}_{\text {comb. }}^{1+h_{\text {bot }}}=\mathrm{p}_{\text {comb. }}^{\prime}+\left(\frac{\mathbf{R h L}}{\mathrm{V}_{\text {comb. }}}\right) \theta_{\text {cyde }}(\gamma-1)
\end{aligned}
$$

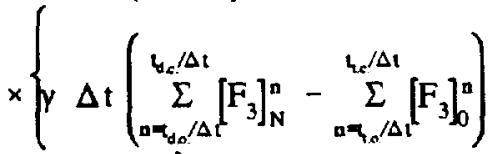

$$
\begin{aligned}
& \left.+\frac{\dot{Q}}{p^{*} \omega R h L}\right\} \text {, }
\end{aligned}
$$

where the subscripts d.o., d.c., t.o., t.c. refer to the delivery port opening and closing times, and transfer port opening and closing times respectively. The term $\dot{Q}$ in equation 20 is the rate of heat addition in the combustor. The combustor pressure and temperature were used as stagnation boundary conditions for the delivery port.

Figure 14 shows a comparison for one test of the model predictions and some pressure taps which were placed in the endwalls or ports of the wave rotor at various circumferential locations. The data has been scaled by the exit static pressure, $p_{0}$ which was ambient. Data from the model was obtained from the image cells at either end of the passage. For this calculation, a value of $y=1.365$ was used which is roughly equal to the mean value of the intake port and the exhaust port. The viscosity used in the model was also an average of these two states. The amount of heat added to the model combustor was adjusted until the ratio of exhaust to intake stagnation temperature matched the experiment. The agreement is excellent and it is noted that the ratio of exhaust to inlet stagnation pressure predicted by the model matched the experiment exactly.

Although the mass flow rate from this particular test was not recorded, other data indicates that the model again overpredicted by approximately $30 \%$.

Figure 15 shows comparisons of the measured versus calculated total pressure and temperature distributions in the exhaust port for the same test conditions from which Figure 14 was made. The data has been scaled by the 

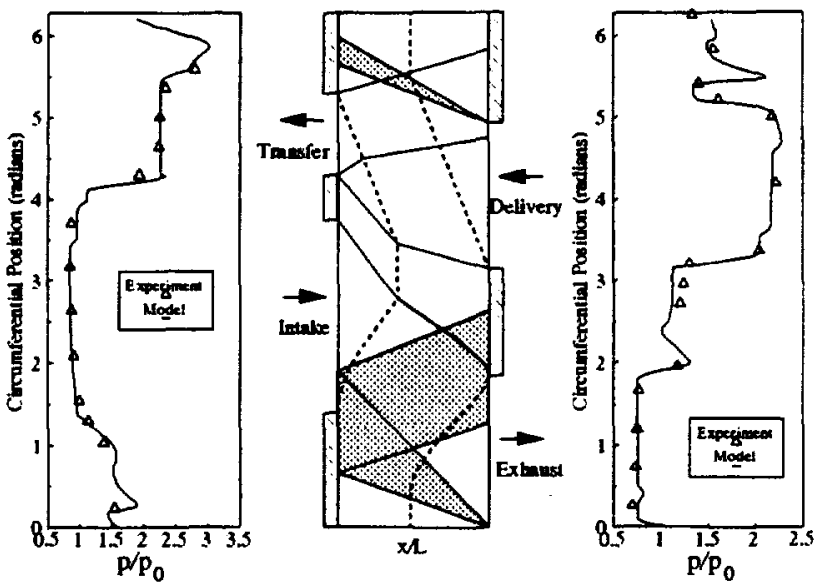

Figure 14 Pressure Trace of G. E. Experiment

inlet stagnation states, P1 and T1. The model agrees reasonably well with the limited number of experimental points available with both experiment and model showing a fairly non-uniform distribution. This seems to be due to mis-timed ports which lead to spurious waves in the cycle. This can clearly be seen in Figure 16 which shows calculated contour plots of pressure, density, and velocity in the passage during one cycle. The exhaust port appears on the lower right side of each contour $(\theta=0.0-1.90$ radians)

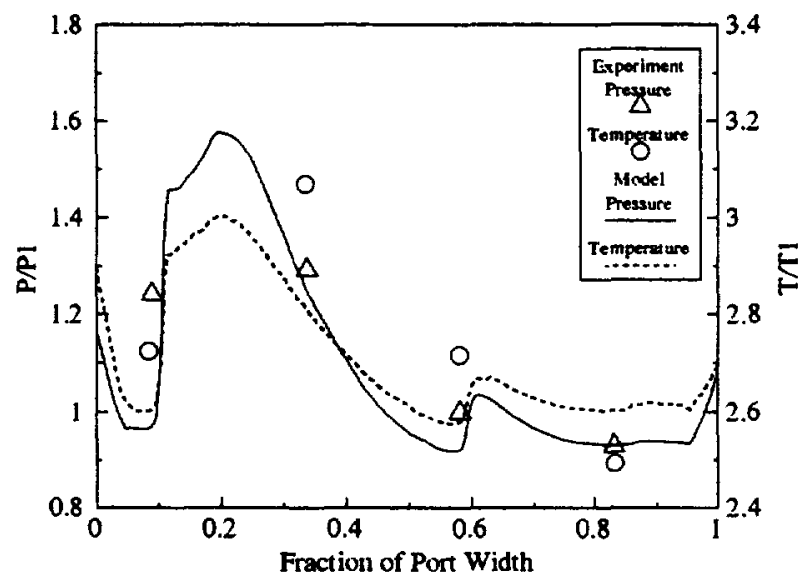

Figure 15 G.E. Exhaust Port Stagnation Pressure and Temperature Distribution

\subsection{Conclusions}

A numerical model has been developed which can predict the performance of a wave rotor, given the geometry and boundary conditions. The model accounts for the important loss mechanisms of viscosity, heat transfer, leakage, and finite opening time. Comparison between the model and three geometrically different wave rotor experiments have yielded good results. The only significant discrepancy lies in the mass flow predictions which are consistently $10-30 \%$ too high.

\section{Acknowledgements}

The author would like to thank Dr. Jack Wilson, who designed and is currently running the NASA Wave Rotor experiment, for (among other things) providing me with excellent data despite numerous unforseen difficulties in the test cell.
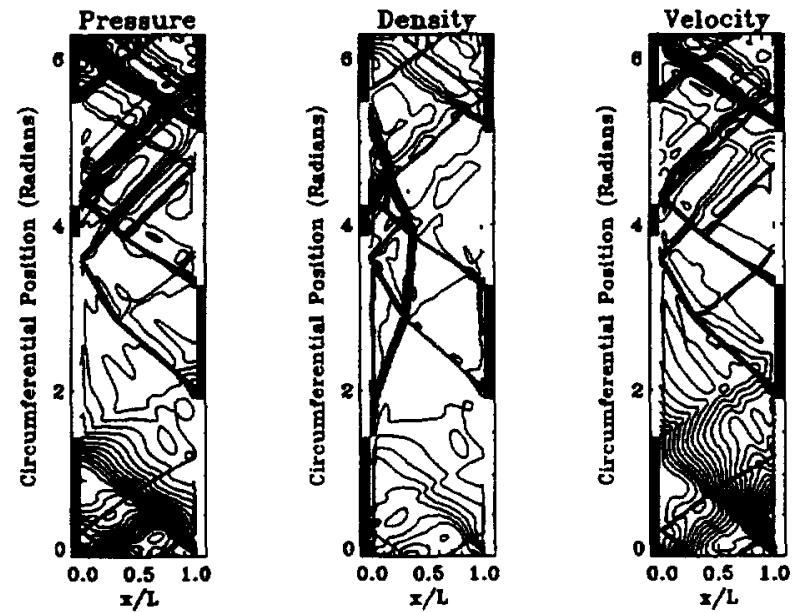

Figure 16 G.E. Cycle Contour Plots

\section{References}

1. Foa, J. V., Elements of Elight Propulsion, John Wiley and Sons, 1960.

2. Kentfield, J. A. C., Nonsteady One-Dimensional Internal Compressible Elows: Theory and Application, Oxford University Press, 1993.

3. Azoury, P.H., Engineering Application of Unsteady Eluid Elow, Wiley and Sons, 1992.

4. Gyarmathy, George, "How Does the Comprex Pressure-Wave Supercharger Work?", SAE paper \# 830234.

5. Taussig, R. T., "Energy Exchanger Performance and Power Cycle Evaluation-Experiments and Analysis", Final Report DOE/ER/01084--T1, 1980.

6. Paxson, D. E., "A General Numerical Model for Wave Rotor Analysis", NASA TM 105740, 1992.

7. Kentfield, J. A. C., "An Examination of the Performance of Pressure Exchanger Equalizers and Dividers", $\mathrm{PhD}$ Thesis, U. of London, 1963 (also in Journal of Basic Engineering, September, 1969).

8. Klapproth, J. F, "Wave Engine Project", General Electric Quarterly Reports, 1960. 
9. Wilson, Jack and Fronek, Dennis, "Initial Results From the NASA-Lewis Wave Rotor Experiment", Presented at the 29th Joint Propulsion Conference, Monterey, CA, 1993, paper \# AIAA 93-2521.

10. Welch, Gerard, "Two-dimensional Numerical Study of Wave Rotor Flow Dynamics", Presented at the 29th Joint Propulsion Conference, Monterey, CA, 1993, paper \# AIAA 93-2525.

11. Larosiliere, L., Three Dimensional Numerical Simulation of Gradual Opening in a Wave Rotor Passage", Presented at the 29th Joint Propulsion Conference, Monterey, CA, 1993, paper \# AIAA 93-2526.

12. Paxson, D. E., "An Improved Numerical Model for Wave Rotor Design and Analysis", presented at The 31 st Annual Aerospace Sciences Meeting, Reno, NV, paper \#AIAA-93-0482, 1993, also NASA TM 105740, 1993.

13. Roe, P. L., "Characteristic Based Schemes for the Euler Equations", Annual Review of Fluid Mechanics, 1986, vol. 18, pp 337-65.

14. Holman, J. P., Heat Transfer, fifth edition, McGraw-Hill Book Company, 1981.

15. Kays, W. M., and Crawford, M. E., Convective Heat and Mass Transfer, McGraw-Hill Book Company, 1980.

16. Egli, A., "The Leakage of Steam Through Labyrinth Seals", Trans. ASME, Vol. 57, 1935, pp 115-122. 


\section{REPORT DOCUMENTATION PAGE}

Public reporting burden for this collection of information is estimated to average 1 hour per response, inctuding the time for reviewing instructions, searching existing data sources, gathering and maintaining the data needed, and completing and reviewing the collection of information. Send comments regarding this burden estimate or any other aspect of this collection of information, including suggestions for reducing this burden, to Washington Headquarters Services, Directorate for Information Operations and Reports, 1215 Jeflt Davis Highway, Suite 1204, Artington, VA 22202-4302, and to the Otfice of Management and Budget, Paperwork Reduction Project (0704-0188), Washington, DC 20503.

\begin{tabular}{|l|l|l} 
1. AGENCY USE ONLY (Leave blank) & $\begin{array}{c}\text { 2. REPORT DATE } \\
\text { June } 1993\end{array}$ & $\begin{array}{r}\text { 3. REPORT TYPE AND DATES COVERED } \\
\text { Technical Memorandum }\end{array}$
\end{tabular}

4. TITLE AND SUBTITLE

5. FUNDING NUMBERS

A Comparison Between Numerically Modelled and Experimentally Measured Loss Mechanisms in Wave Rotors

6. AUTHOR(S)

WU-505-62-50

Daniel E. Paxson

\section{PERFORMING ORGANIZATION NAME(S) AND ADDRESS(ES)}

National Aeronautics and Space Administration

Lewis Research Center

Cleveland, Ohio 44135-3191

9. SPONSORING/MONTORING AGENCY NAME(S) AND ADDRESS(ES)

National Aeronautics and Space Administration

Washington, D.C. 20546-0001
8. PERFoRMING ORGANIZATION REPOAT NUMBER

E-8018

11. SUPPLEMENTARY NOTES

Prepared for the 29th Joint Propulsion Conference and Exhibit sponsored by the AIAA, SAE, ASME, and ASEE, Monterey, California, June 28-30, 1993. Responsible person, Daniel E. Paxson, (216) 433-8334.

12a. DISTRIBUTION/AVAILABILITY STATEMENT

12b. DISTRIBUTION CODE

Unclassified - Unlimited

Subject Category 07

13. ABSTRACT (Maximum 200 words)

A numerical model has been developed which is capable of predicting the performance of a wave rotor (pressure exchanger) of specified geometry over a wide range of operating conditions. The model can account for the major loss mechanisms of leakage from the tube ends, fluid viscosity, heat transfer to the tube walls, finite tube opening time, shock waves, and non-uniform port flows. It is a one dimensional flow model which follows a single tube as it rotates past the various stationary ports. Since the model is relatively simple (i.e. one dimensional) it uses little computer time. This makes it suitable for design as well as analytical purposes. This paper will present a brief description of the model then discuss a comparison between the model predictions and several wave rotor experiments.

\begin{tabular}{|c|c|}
\hline 14. SUBJECT TERMS \\
Wave rotor; Numerical; Simulation \\
\hline $\begin{array}{c}\text { 17. SECURITY CLASSIFICATION } \\
\text { OF REPORT } \\
\text { Unclassified }\end{array}$ & $\begin{array}{c}\text { 18. SECURIT CLASSIFICATION } \\
\text { OF THIS PAGE } \\
\text { Unclassified }\end{array}$ \\
\hline
\end{tabular}

19. SECURTY CLASSIFICATION
OF ABSTRACT
Unclassified

